\title{
Comparison of three different anti-Xa assays in major orthopedic surgery patients treated with direct oral anticoagulant
}

\author{
Makoto Ikejiri ${ }^{1}$, Hideo Wada ${ }^{2,6^{*}}$ (D), Shine Tone ${ }^{3}$, Hiroki Wakabayashi ${ }^{3}$, Masahiro Hasegawa ${ }^{3}$, Takeshi Matsumoto ${ }^{4}$, \\ Naoki Fujimoto ${ }^{2}$, Norikazu Yamada ${ }^{5}$, Masaaki Ito ${ }^{5}$, Kaname Nakatani ${ }^{1}$ and Akihiro Sudo ${ }^{3}$
}

\begin{abstract}
Background: Measurement of edoxaban plasma concentration has been gathering attention in major orthopedic surgery patients receiving edoxaban for the prevention of venous thromboembolism (VTE).

Methods: The anti-Xa activity was measured one hour after edoxaban intake using 3 different assays in 200 patients after major orthopedic surgery.

Results: The anti-Xa activities on Day 8 were significantly higher than those on Day 4 and those on Day 4 were significantly higher than those on Day 1. The anti-Xa activities in two assays closely correlated with each other, but the other anti-Xa assay did not correlated with other two assays. The anti-Xa activities as detected in the three Xa assays were significantly higher in the patients without deep vein thrombosis (DVT) than in those with DVT on Day 4. Additionally, there were no significant differences in the anti-Xa activities of assays $A, B$ and $C$ between patients with and without massive bleeding (MB) on Days 1, 4, 8 and 15.
\end{abstract}

Conclusion: The results of this study suggest that anti-Xa level could be predictive of the risk of VTE, but not of the risk of massive bleeding.

Keywords: Deep vein thrombosis (DVT), Anti-Xa activity, DOAC, Prophylaxis, Orthopedic surgery

\section{Background}

Major orthopedic surgery is associated with a high rate of postoperative venous thromboembolism (VTE) $[1,2]$. The incidence of VTE, such as deep vein thrombosis (DVT) and pulmonary embolism (PE), is reported to range from $42 \%$ to $57 \%$ after total hip arthroplasty (THA) and $41 \%$ to $85 \%$ after total knee arthroplasty (TKA) [3] in the absence of thromboprophylaxis. VTE is one of the most prevalent cardiovascular diseases [4-6] and a major complication of major orthopedic or abdominal surgery. PE is a potentially fatal disease and is typically caused by proximal DVT. As patients with PE have non-specific and highly variable symptoms, and the imaging tests for a definitive diagnosis are expensive, the

\footnotetext{
*Correspondence: wadahide@clin.medic.mie-u.ac.jp

${ }^{2}$ Department of Molecular and Laboratory Medicine, Mie University Graduate

School of Medicine, Tsu, Japan

${ }^{6}$ Department of Laboratory Medicine, Mie University Graduate School of

Medicine, 2-174 Edobashi, Tsu -City Mie-ken 514-8507, Japan

Full list of author information is available at the end of the article
}

early diagnosis of PE is often difficult [7-9]. Therefore, preventing the development of VTE is clinically important after surgery.

The efficacy of low-molecular-weight heparins (LMWH) $[10,11]$ and fondaparinux $[12,13]$ for VTE prophylaxis has been established in major orthopedic surgery patients. However, there are a few cases of massive bleeding (MB) in patients receiving LMWH or fondaparinux [14-16]. Direct oral anticoagulants (DOACs) including both direct factor Xa inhibitors (rivaroxaban, apixaban and edoxaban) and the direct thrombin inhibitor (dabigatran) have shown a non-inferior effect for VTE prophylaxis compared to conventional prophylaxis [17].

The levels of LMWH, fondaparinux and DOACs cannot be monitored by routine assays such as activated partial thromboplastin time (APTT) or prothrombin time (PT); therefore, drug-specific anti-Xa assays use a chromogenic substrate to measure the concentration of anticoagulants that inhibit factor $\mathrm{Xa}$ in patients being 
treated with LMWH, fondaparinux or DOACs [18]. The anti-Xa activity results are reported to correlate with the weight and body mass index (BMI) and to predict $\mathrm{MB}$ in orthopedic patients with a normal renal function treated with fondaparinux [19].

We evaluated the anti-Xa activity measured using 3 different chromogenic anti-Xa assays (two assays available in Japan for the measurement of heparin and fondaparinux respectively, and one edoxaban-specific investigational assay) in 200 patients who underwent major orthopedic surgery and were treated with edoxaban for the prophylaxis of DVT in order to (i) examine the relationships between the results generated with these 3 assays and (ii) to investigate the potential clinical relevance of test results.

\section{Methods}

\section{Patients}

Patients presenting for THA and TKA at Mie University Hospital from January 1, 2014, to December 31, 2015 and receiving edoxaban $30 \mathrm{mg}$ (Daiichi-Sankyo, Tokyo, Japan) once daily for VTE prophylaxis were enrolled in the study.

Screening for DVT was performed by a whole-leg compression ultrasound examination using the standardized ultrasound criteria for venous non-compressibility before the operation, as well as on Day 4 and 14 [20].

\section{Anti-Xa activity}

Anti-Xa activity was measured prospectively on Days 1, 4,8 and 15. Blood was drawn one hour after drug intake on Days 1, 4 and 8 and $12 \mathrm{~h}$ after the last drug intake on Day 15.

The anti-Xa activity of edoxaban was measured using (i) Testzym Heparin S (Sekisui Medical Co., Ltd., Tokyo, Japan) on the Coagrex 800 System (Sekisui; assay A) $[15,19]$; (ii) $\mathrm{STA}^{\oplus}$-Liquid Anti-Xa (Stago, Asnières-sur-Sreine, France) on STA -R Evolution coagulometer (Stago; assay B) with a dedicated test set-up [21]; and (iii) $\mathrm{HemosIL}^{\circ}$ Liquid Heparin (Instrumentation Laboratory; Bedford, MA, USA) on ACL-TOP (Instrumentation Laboratory; assay C) [21, 22].
Assay A was calibrated using a fondaparinux-specific standard and results were expressed in fondaparinux $\mathrm{mg} / \mathrm{L}$. Assay B was calibrated using a edoxaban-specific calibrator set (STA Edoxaban calibrator) and verified using an edoxaban-specific control set (STA Edoxaban Control), both developed by Stago. Assay C was calibrated using the HemosIL Liquid Heparin Calibrator (Instrumentation Laboratory). Results for assay $\mathrm{C}$ were expressed in heparin international units (IU)/mL. Assay A contains additional antithrombin (AT) in the assay system, while assays $B$ and $C$ do not.

\section{Statistical analysis}

The data are expressed as the medians and 25th-75th percentiles. The differences between the groups were examined using the Mann-Whitney U-test. The analysis among 4 groups was performed by the one-factor analysis of variance (ANOVA). The correlation was analysed by Spearman's rank correlation coefficient. A $p$-value $<0.05$ was considered to be statistically significant. All statistical analyses were performed using the Stat Flex, version 6, software package (Artec Co. Ltd., Osaka, Japan).

\section{Results}

Two hundred orthopedic patients, including 134 THA and 66 TKA cases, treated with edoxaban and intermittent pneumatic compression for DVT prophylaxis from January 1, 2014, to December 31, 2015, were enrolled in this study (Table 1). These patients received $30 \mathrm{mg}$ of edoxaban by oral administration once a day for 14 days beginning $24 \mathrm{~h}$ after the discontinuation of lumbar anesthesia. Of these 200 patients, 52 exhibited DVT, and 21 patients had $\mathrm{MB}$, defined as a reduction in the hemoglobin level by $>2 \mathrm{~g} / \mathrm{dl}$ compared with that at Day 1 or a hemoglobin level $<7 \mathrm{~g} / \mathrm{dl}$ [15]. As the registration for this trial was late in 26 patients, the Day 1 samples were not obtained in these patients. The sampling was also stopped after complication with DVT or MB.

The anti-Xa activities on Day 8 (assay A $[p<0.01]$, $0.24 \mathrm{mg} / \mathrm{L}[0.11-0.36 \mathrm{mg} / \mathrm{L}] ;$ assay $B[\mathrm{p}<0.01]$, $0.16 \mathrm{mg} / \mathrm{L}[0.09-0.26 \mathrm{mg} / \mathrm{L}]$; assay $\mathrm{C}$ [not significant], $0.81 \mathrm{IU} / \mathrm{mL}[0.25-1.37 \mathrm{IU} / \mathrm{mL}])$ were higher than those

Table 1 Anti-Xa activities in orthopedic patients with or without massive bleeding

\begin{tabular}{|c|c|c|c|c|c|c|}
\hline & \multicolumn{6}{|l|}{ Anti-Xa activity } \\
\hline & \multicolumn{2}{|l|}{$\mathrm{A}(\mathrm{mg} / \mathrm{L})$} & \multicolumn{2}{|l|}{$\mathrm{B}(\mathrm{mg} / \mathrm{L})$} & \multicolumn{2}{|l|}{$\mathrm{C}(\mathrm{IU} / \mathrm{mL})$} \\
\hline & With MB & Without MB & With MB & Without MB & With MB & Without MB \\
\hline Day one & $0.08(0.03-0.14)$ & $0.08(0.01-0.22)$ & $0.05(0.00-0.13)$ & $0.08(0.01-0.15)$ & $0.29(0.01-0.54)$ & $0.32(0.03-0.81)$ \\
\hline Day four & $0.21(0.09-0.28)$ & $0.20(0.06-0.31)$ & $0.14(0.07-0.18)$ & $0.13(0.04-0.23)$ & $0.61(0.25-1.01)$ & $0.69(0.15-1.30)$ \\
\hline Day eight & $0.13(0.05-0.25)$ & $0.24(0.12-0.37)$ & $0.11(0.02-0.20)$ & $0.16(0.09-0.26)$ & $0.70(0.13-1.28)$ & $0.81(0.25-1.41)$ \\
\hline Day fifteen & $0.02(0.00-0.04)$ & $0.03(0.01-0.06)$ & $0.01(0.01-0.02)$ & $0.02(0.01-0.03)$ & $0.03(0.00-0.09)$ & $0.08(0.04-0.13)$ \\
\hline
\end{tabular}

There were no significant differences in the anti-Xa activities according to the assay used between the patients with and without massive bleeding $M B$ massive bleeding 
on Day 4 (assay A, $0.20 \mathrm{mg} / \mathrm{L}$ [0.06-0.31 mg/L]; assay B, $0.13 \mathrm{mg} / \mathrm{L}$ [0.04-0.23 mg/L]; assay C, $0.68 \mathrm{IU} / \mathrm{mL}$ [0.17$1.25 \mathrm{IU} / \mathrm{mL}$ ] and the those levels (on Day 4) were significantly higher than those on Day 1 (assay A, $0.08 \mathrm{mg} / \mathrm{L}$ [0.01-0.21 mg/L]; assay $B, 0.07 \mathrm{mg} / \mathrm{L}[0.01-0.15 \mathrm{mg} / \mathrm{L}]$; assay $\mathrm{C}, 0.31 \mathrm{IU} / \mathrm{mL}[0.03-0.76 \mathrm{IU} / \mathrm{mL}])(p<0.001$ for each) (Fig. 1a-c). ANOVA showed that the variation between subgroup was significant $(\mathrm{p}<0.001$, respectively) in three assays. The anti-Xa activities in assay A closely correlated with those in assay B $(\mathrm{Y}=0.018+0.565 \mathrm{X}$, $r=0.876$ and $\mathrm{p}<0.001)$, but the correlations between assays $\mathrm{A}$ and $\mathrm{C}(0.251+1.704 \mathrm{X}, \quad r=0.455$ and $p<0.001)$ and assays B and C $(0.056+0.086 \mathrm{X}, r=0.496$ and $\mathrm{p}<0.001$ ) were not close (Fig. 2a, b, and c).

The anti-Xa activities were significantly higher in the patients without DVT than in those with DVT on Day 4 (assay A: $p<0.01$, assays $\mathrm{B}$ and $\mathrm{C}: p<0.05$ ) and the anti-Xa activities of assay B and C ( $p<0.001$ for both) were significantly higher in the patients with DVT than in those without DVT on Day 15 (Fig. 3a-c). ANOVA showed that the variation between subgroup was significant ( $p<0.001$, respectively) in three assays. The antiXa activity in more than half of DVT patients was significantly low on Day 4. Although there were no significant differences in the anti-Xa activities between on Days 1 and 4 in the patients with DVT, the anti-Xa activities of assays $A, B$ and $C$ in patients without DVT were significantly higher $(\mathrm{p}<0.001$, respectively) on Day 4 than on Day $1(\mathrm{p}<0.001)$. In addition, there were no significant differences in the anti-Xa activities of assays $\mathrm{A}, \mathrm{B}$ and $\mathrm{C}$ between patients with and without MB on Day 1, 4, 8 and 15 (Table 1).

\section{Discussion}

Global coagulation tests such as APTT and PT are not recommended for selective anti-Xa drug plasma level evaluation due to inconsistent sensitivity across drugs and reagents and a lack of specificity with these assays; an anti-Xa assay is required to monitor these drugs [18]. However several issues have been encountered with anti-Xa assays, such as their complicated nature, cost and a little evidences supporting their clinical use, except in emergency situations (e.g. major bleeding, surgery or invasive procedure). Although three different anti-Xa assays are available, there have been few reports comparing the results of these assays [23]. In a previous report [23], the activities detected with these assays were well correlated in patients treated with fondaparinux. In the present study, the anti-Xa activities in assay A closely correlated with those in assay $\mathrm{B}$, but the correlations were poor between assays $A$ and $C$ and assays $B$ and $C$. Anti-Xa assay A contains additional AT in the assay system, while anti-Xa assays $\mathrm{B}$ and $\mathrm{C}$ do not, suggesting that the existence of AT was not the cause for the poor
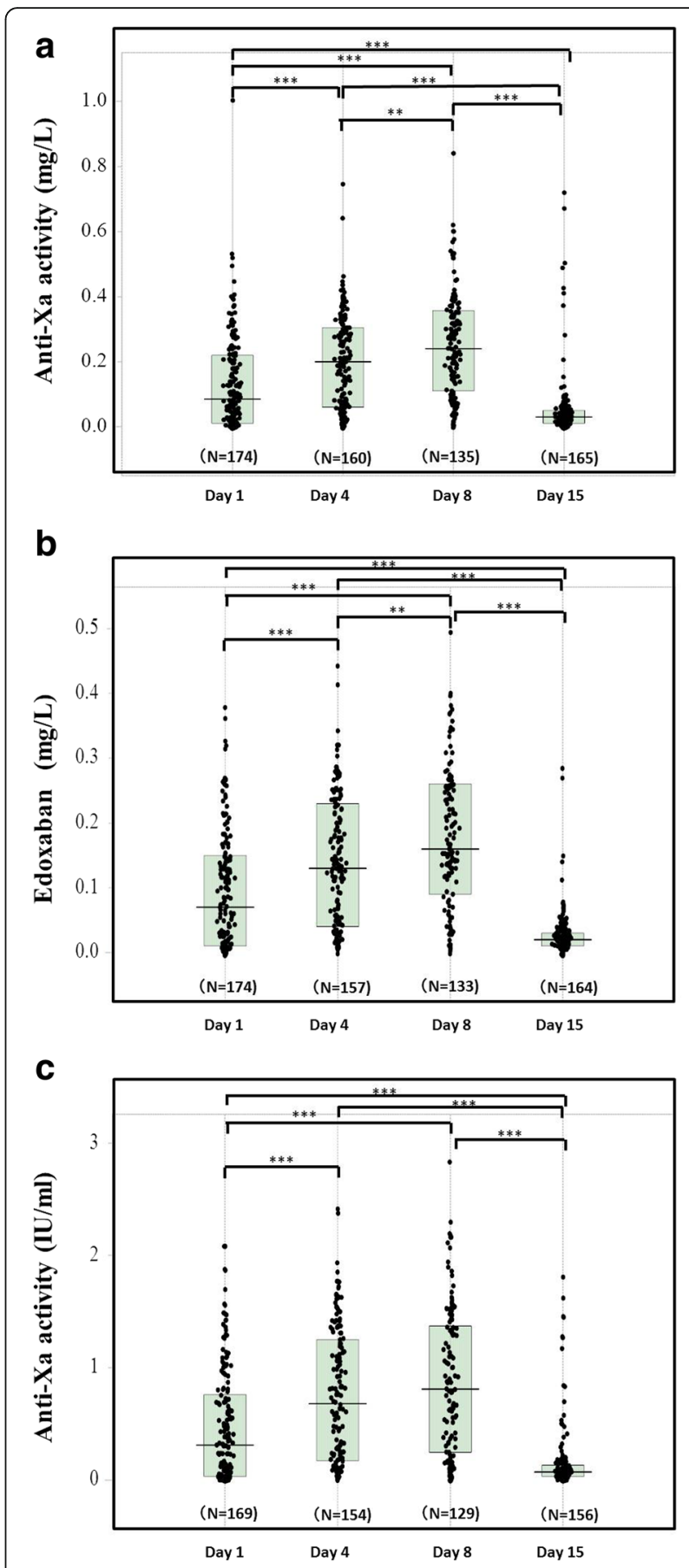

Fig. 1 The anti-Xa activity (A), (B) and (C) in orthopedic patients treated with edoxaban during TKA or THA. The anti-Xa activities of A kit (a), B kit (b) and $C$ kit (c) in orthopedic patients treated with edoxaban on Days 1, 4, 8 and 15. ***, $p<0.001 ;{ }^{* *}, p<0.01 ;{ }^{*}, p<0.05$

correlation in the anti-Xa activity. Instead, the poor correlation may have been due to the fact that DOAC is a direct anticoagulant for Xa without activation of AT.

There are nevertheless limitations to the comparison of the three assays used in this study. In fact, one has to keep in mind that assays should preferably use for the 


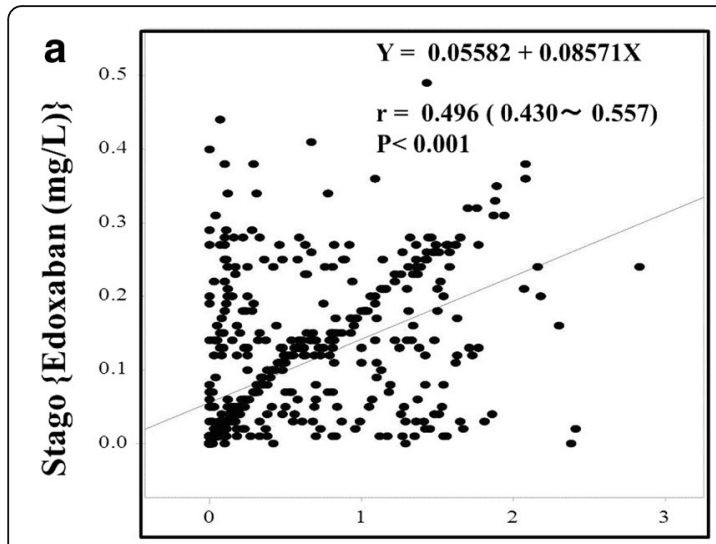

IL $\{$ Anti-Xa activity (IU/ml)\}
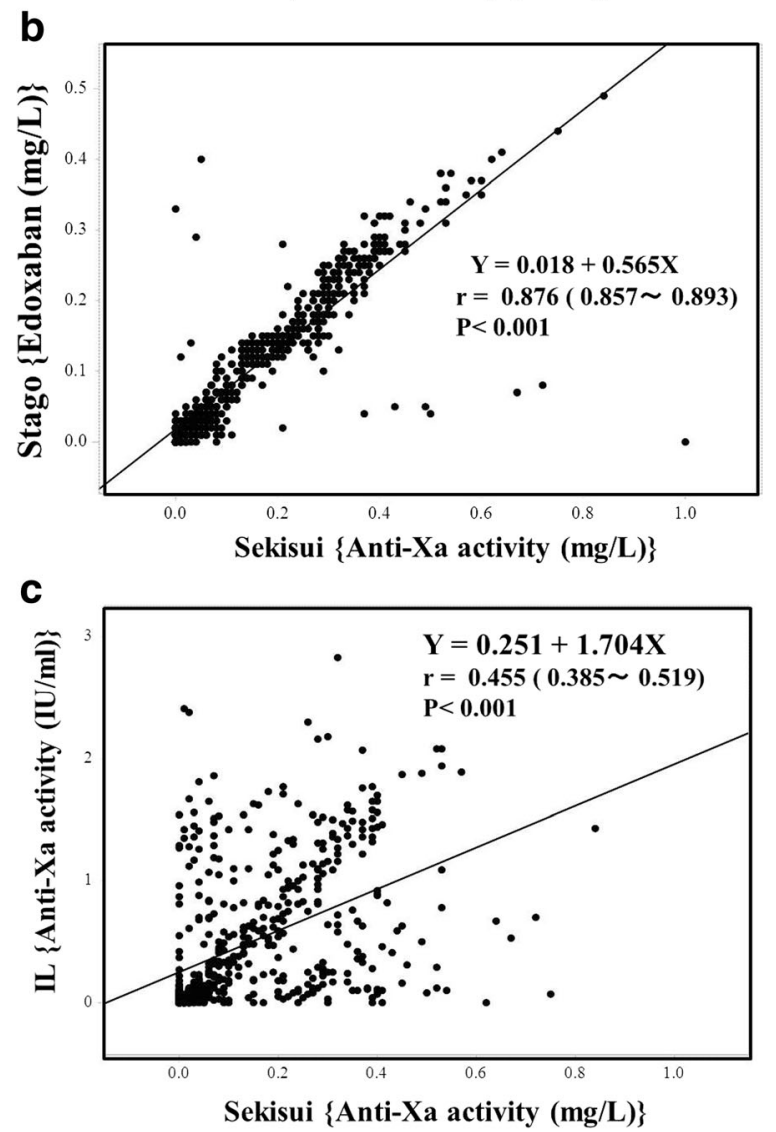

Fig. 2 Correlation between the anti-Xa activities of $A$ and $B$ assay (a), A and C assay (b) and B and C assay (c)

indication that they have designed for. Even though heparin, fondaparinux and edoxaban exhibit anti-Xa activity, they differ in many ways [24].

The distribution of anti-Xa activity ranged more widely in the patients treated with edoxaban than in those treated with fondaparinux $[15,23]$. This wide distribution in the anti-Xa activity of edoxaban may be the cause of the characteristic pharmacokinetics and pharmacodynamics of edoxaban [25]. The anti-Xa activity gradually

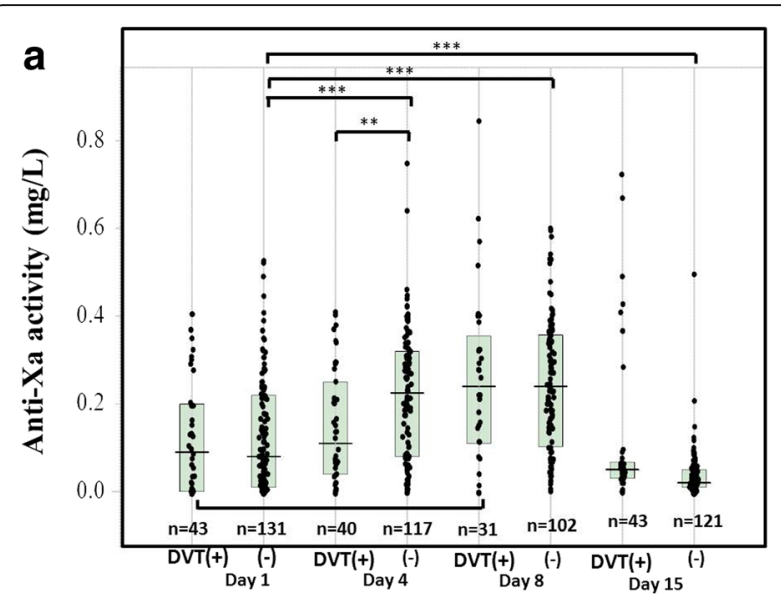

b

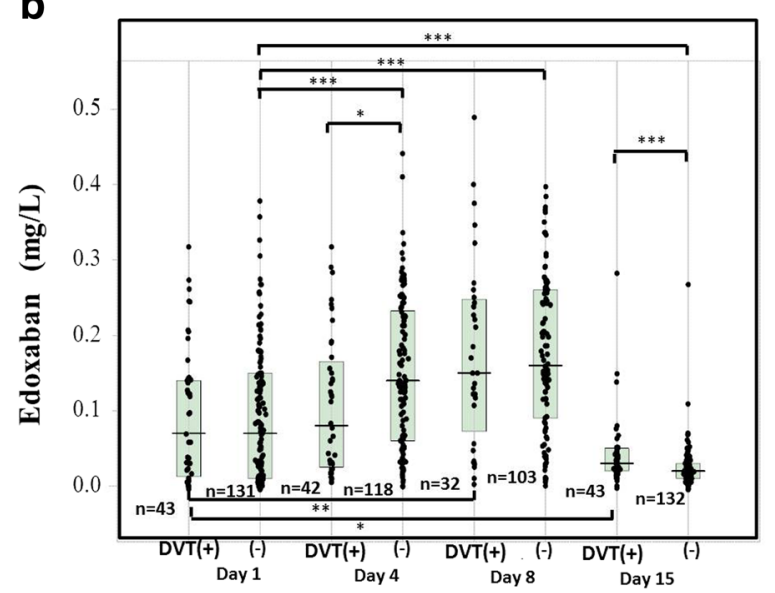

C

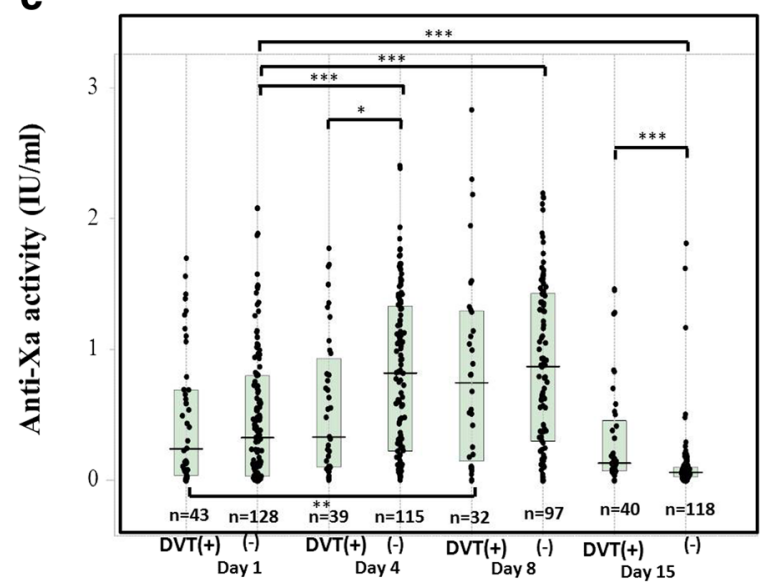

Fig. 3 The anti-Xa activity in orthopedic patients with and without DVT treated with edoxaban during TKA or THA. The anti-Xa activities of $A$ kit (a), B kit (b) and C kit (c) in orthopedic patients treated with edoxaban on Day 1, 4, 8 and 15. ${ }^{* *}, p<0.001 ;{ }^{* *}, p<0.01 ;{ }^{*}, p<0.05$

increased from Day 1 to 8 , suggesting that the anti-Xa activity may accumulate, necessitating anti-Xa monitoring in patients being treated with edoxaban. As an anti-Xa activity was not high in the patients treated with edoxaban 
comparison with fondaparinux, low frequency of $\mathrm{MB}$ was observed in this study.

The anti-Xa activities were significantly lower in the patients with DVT than in those without DVT on Day 4 , suggesting that lower anti-Xa activity may be a one of the causes for DVT in patients being treated with edoxaban. However, there were no significant differences in the anti-Xa activities detected by the assays between patients with and without $\mathrm{MB}$, suggesting that anti-Xa activities may not be useful for predicting $\mathrm{MB}$ in these patients. These findings differed between fondaparinux and edoxaban treatments. Several reports $[15,19,26]$ have shown that there were no significant differences in the anti-Xa activities between patients with and without DVT receiving fondaparinux treatment following major orthopedic surgery. These differences may be due to the differences in the mechanism for anticoagulation of these drugs; fondaparinux activates AT to inhibit Xa, while edoxaban directly inhibits Xa. Although the treatment of VTE requires high anti-Xa activity [27], VTE prophylaxis after orthopedic surgery may not require high anti-Xa activity [25]. Furthermore, the frequency of $M B$ after orthopedic surgery in patients treated with edoxaban in this study may have been low compared with previous studies in patients treated with fondaparinux $[15,26]$.

\section{Conclusion}

Although the three anti-Xa assays were not closely correlated with each other, these activities were significantly lower in the patients with DVT than in those without. There were no significant differences among the three assays regarding the usefulness of monitoring edoxaban treatment in orthopedic patients.

\section{Abbreviations \\ APTT: Activated partial thromboplastin time; AT: Antithrombin; BMI: Body mass index; DOACs: Direct oral anticoagulants; DVT: Deep vein thrombosis; LMWH: Low-molecular-weight heparins; MB: Massive bleeding; PE: Pulmonary embolism; PT: Prothrombin time; THA: Total hip arthroplasty; TKA: Total knee arthroplasty; VTE: Venous thromboembolism}

\section{Acknowledgements}

None.

\section{Funding}

This work was supported in part by a Grant-in-Aid from the Ministry of Health, Labour and Welfare of Japan and the Ministry of Education, Culture, Sports, Science and Technology of Japan and fund from Sekisui Medical Co. Ltd., Stago and Instrumentation Laboratory.

\section{Availability of data and materials}

None.

\section{Authors' contributions}

$\mathrm{Ml}$ and KN assayed anti-Xa assay, ST, HW, MH and AS managed the patients, TM analyzed data, NF, NY and MI diagnosed VTE, and HW wrote the manuscript according to the above analysis. All members discussed this manuscript. All authors read and approved the final manuscript.

\section{Ethics approval and consent to participate}

The study protocol was approved by the Human Ethics Review Committee of the Mie University School of Medicine, and a signed consent form was obtained from each subject. This study was faithfully carried out in accordance with the principles of the Declaration of Helsinki.

\section{Consent for publication}

A signed consent form was obtained from each subject.

\section{Competing interests}

The three different Anti-Xa assays used in this study were provided by Sekisui Medical Co. Ltd., Stago and Instrumentation Laboratory.

\section{Publisher's Note}

Springer Nature remains neutral with regard to jurisdictional claims in published maps and institutional affiliations.

\section{Author details}

${ }^{1}$ Department of Central Laboratory, Mie University Graduate School of Medicine, Tsu, Japan. ${ }^{2}$ Department of Molecular and Laboratory Medicine, Mie University Graduate School of Medicine, Tsu, Japan. ${ }^{3}$ Department of Orthopaedic Surgery, Mie University Graduate School of Medicine, Tsu, Japan. ${ }^{4}$ Department of Blood Transfusion Service, Mie University Graduate School of Medicine, Tsu, Japan. ${ }^{5}$ Department of Cardiology and Nephrology, Mie University Graduate School of Medicine, Tsu, Japan. ${ }^{6}$ Department of Laboratory Medicine, Mie University Graduate School of Medicine, 2-174 Edobashi, Tsu -City Mie-ken 514-8507, Japan.

Received: 8 August 2017 Accepted: 14 September 2017

Published online: 12 October 2017

\section{References}

1. Geerts WH, Heit JA, Clagett P, Pineo GF, Colwell CW, Anderson FA Jr, et al. Prevention of venous thromboembolism. Chest. 2001;119:S132-75.

2. Piovella F, Wang CJ, Lu H, Lee K, Lee LH, Lee WC, et al. AIDA investigators: Deep-vein thrombosis rates after major orthopedic surgery in Asia. An epidemiological study based on postoperative screening with centrally adjudicated bilateral venography. J Thromb Haemost. 2005;3:2664-70.

3. Geerts WH, Pineo GF, Heit JA, Bergqvist D, Lassen MR, Colwell CW, et al. Prevention of venous thromboembolism: the seventh ACCP conference on antithrombotic and thrombolytic therapy. Chest. 2004;126:338S-400S.

4. van der Hulle T, Dronkers CE, Huisman MV, Klok FA. Current standings in diagnostic management of acute venous thromboembolism: still rough around the edges. Blood Rev. 2015; (in press)

5. Cohen AT, Agnelli G, Anderson FA, Arcelus Jl, Bergqvist D, Brecht JG, et al. VTE impact assessment Group in Europe (VITAE): venous thromboembolism (VTE) in Europe. The number of VTE events and associated morbidity and mortality. Thromb Haemost. 2007;98:756-64.

6. Heit JA. The epidemiology of venous thromboembolism in the community. Arterioscler Thromb Vasc Biol. 2008;28:370-2.

7. Geersing GJ, Zuithoff NP, Kearon C, Anderson DR, Ten Cate-Hoek AJ, Elf JL, et al. Exclusion of deep vein thrombosis using the wells rule in clinically important subgroups: individual patient data meta-analysis. BMJ. 2014;348:g1340.

8. Aujesky D, Roy PM, Verschuren F, Righini M, Osterwalder J, Egloff M, et al. Outpatient versus inpatient treatment for patients with acute pulmonary embolism: an international, open-label, randomised, non-inferiority trial. Lancet. 2011;378:41-8.

9. Righini M, Le Gal G, Aujesky D, Roy PM, Sanchez O, Verschuren F, Rutschmann O, et al. Diagnosis of pulmonary embolism by multidetector $C T$ alone or combined with venous ultrasonography of the leg: a randomised non-inferiority trial. Lancet 2008;371:1343-52.

10. Leclerc JR, Gent M, Hirsh J, Geerts WH, Ginsberg JS. The incidence of symptomatic venous thromboembolism after enoxaparin prophylaxis in lower extremity arthroplasty: a cohort study of 1984 patients. Canadian Collaborative Group Chest. 1998;114:115S-8S.

11. Heit JA, Elliott CG, Trowbridge AA, Morrey BF, Gent M, Hirsh J. Ardeparin sodium for extended out-of-hospital prophylaxis against venous thromboembolism after total hip or knee replacement: a randomized, double-blind, placebo-controlled trial. Ann Intern Med. 2000;132:853-61. 
12. Bauersachs RM. Fondaparinux: an update on new study results. Eur J Clin Investig. 2005;35:27-32.

13. Turpie AG, Gallus AS, Hoek JA. Pentasaccharide Investigators: A synthetic pentasaccharide for the prevention of deep-vein thrombosis after total hip replacement. N Engl J Med. 2001;344:619-25.

14. Sasaki S, Miyakoshi N, Matsuura H, Saitoh H, Kudoh D, Shimada Y. Prospective randomized controlled trial on the effect of fondaparinux sodium for prevention of venous thromboembolism after hip fracture surgery. J Orthop Sci. 2009;14:491-6.

15. Yoshida K, Wada H, Hasegawa M, Wakabayashi H, Matsumoto T, Shimokariya Y, et al. Increased fibrinolysis increases bleeding in orthopedic patients receiving prophylactic fondaparinux. Int J Hematol. 2012;95:160-6.

16. Hannon MG1, Lamont JG. Compartment syndrome due to massive leg hematoma after primary total hip arthroplasty: a previously unreported complication of fondaparinux. J Arthroplasty. 2012;27:1414. e9-e11.

17. Feng W, Wu K, Liu Z, Kong G, Deng Z, Chen S, Wu Y, Chen M, Liu S, Wang H. Oral direct factor $X a$ inhibitor versus enoxaparin for thromboprophylaxis after hip or knee arthroplasty: systemic review, traditional meta-analysis, dose-response meta-analysis and network meta-analysis. Thromb Res. 2015; 136:1133-44.

18. Gehrie E, Laposata M. Test of the month: the chromogenic antifactor Xa assay. Am J Hematol. 2012:87:194-6.

19. Yoshida K, Wada H, Hasegawa M, Wakabayashi H, Ando H, Oshima S, et al. Monitoring for anti-Xa activity for prophylactic administration of Fondaparinux in patients with artificial joint replacement. Int J Hematol. 2011;94:355-60.

20. Schellong SM, Schwarz T, Halbritter K, Beyer J, Siegert G, Oettler W, et al. Complete compression ultrasonography of the leg veins as a single test for the diagnosis of deep vein thrombosis. Thromb Haemost. 2003;89:228-34.

21. Gouin-Thibault I, Flaujac C, Delavenne X, Quenet S, Horellou MH, Laporte S, et al. Assessment of apixaban plasma levels by laboratory tests: suitability of three anti-Xa assays. A multicentre French GEHT study. Thromb Haemost. 2014;111:240-8.

22. Gosselin RC, Francart SJ, Hawes EM, Moll S, Dager WE, Adcock DM. Heparincalibrated chromogenic anti-Xa activity measurements in patients receiving rivaroxaban: can this test be used to quantify drug level? Ann Pharmacother. 2015:49:777-83.

23. Ikejiri M, Wada H, Yamaguchi T, Miyazaki S, Hasegawa M, Wakabayashi $H$, Asanuma K, Sakaguchi A, Matsumoto T, Ohishi K, Fujimoto N, Yamada N, Ito M, Katayama N, Sudo A. Comparison of three different anti-Xa assays in major orthopedic surgery patients treated with fondaparinux. Int J Hematol. 2016;103:554-9.

24. Siguret V, Gouin-Thibault I, Gaussem P, Pautas E. Optimizing the use of anticoagulants (heparins and oral anticoagulants) in the elderly. Drugs Aging. 2013;30:687-99.

25. Parasrampuria DA, Truitt KE. Pharmacokinetics and pharmacodynamics of edoxaban, a non-vitamin $\mathrm{K}$ antagonist oral anticoagulant that inhibits clotting factor Xa. Clin Pharmacokinet. 2016;55:641-55.

26. Hasegawa M, Wada H, Wakabayashi H, Yoshida K, Miyamoto N, Asanuma K, et al. The relationships among hemostatic markers, the withdrawal of fondaparinux due to a reduction in hemoglobin and deep vein thrombosis in Japanese patients undergoing major orthopedic surgery. Clin Chim Acta. 2013:425:109-13

27. Ota S, Wada H, Mastuda A, Ogihara Y, Yamada N, Nakamura M, Ito M. Anti-Xa activity in VTE patients treated with fondaparinux. Clin Chim Acta. 2015;442:22-3.

\section{Submit your next manuscript to BioMed Central and we will help you at every step:}

- We accept pre-submission inquiries

- Our selector tool helps you to find the most relevant journal

- We provide round the clock customer support

- Convenient online submission

- Thorough peer review

- Inclusion in PubMed and all major indexing services

- Maximum visibility for your research

Submit your manuscript at www.biomedcentral.com/submit

Biomed Central 